\title{
SEKELUMIT TENTANG RISALAH “POETICS”, KARYA ARISTOTLE (384-322 SM)
}

\author{
Aditya Nirwana ${ }^{1}$ \\ ${ }^{1}$ Universitas Ma Chung, aditya.nirwana@machung.ac.id
}

\section{PENDAHULUAN}

DALAM risalah Poetics, Aristotle menyajikan pokok-pokok pemikirannya tentang estetika, khususnya drama. Beberapa hal didalamnya meliputi bentuk plot dan perwatakan dalam drama, perumitan, perbedaan diantara beragam jenis puisi atau tragedi, dirthyramb, komedi, iambic, drama, ainos, diagramma, satire, poemata, epic, rhetoric, amphi geneseos, dan juga accoustic. Beberapa istilah tersebut mungkin mewakili bentuk-bentuk seni drama yang ada dalam seni Yunani Klasik, yang keberadaannya hanya dapat dipahami dalam konteks kebudayaan Yunani Klasik. Mengenai pokok-pokok pemikiran estetika yang disampaikan Aristotle dalam Poetics, hal ini masih juga menuai perdebatan. Dalam Art and Aesthetic in Aristotle, Marshall mengatakan bahwa Poetics tidak menghadirkan teori estetika, namun ia merupakan sebuah analisis yang dilakukan Aristotle terhadap metode penciptaan karya sastra. Imitasi adalah metode konstuksi artistik, namun bukanlah kriteria keindahan. Poetics bukanlah petunjuk praktis (manual) estetika, ia juga tidak memberitahu bagaimana sifat-sifat keindahan itu, ia hanya memberi tahu bagaimana drama yang bagus diproduksi, dan juga metode kritik untuk menemukan nilai kesusastraan dari produksi drama.1 Hal ini memang dapat dipahami karena memang dalam Poetics, Aristotle mengatakan imitasi sebagai 'the manner' atau 'mode', yang dapat dipahami sebaga 'cara', atau metode. 2

Tidak ada yang keliru dengan apa yang disampikan oleh Marshall, termasuk juga saat ia menyayangkan banyaknya orang yang menjadikan Poetics sebagai petunjuk praktis estetika. Terkait dengan hal tersebut, nampaknya ada beberapa hal yang mungkin perlu dipertimbangkan. Nampaknya Marshall memandang estetika sebagai salah satu cabang filsafat yang membahas mengenai keindahan, atau dengan perkataan lain, sebagai filsafat keindahan (philosophy of beauty). Sebagai gugus filsafat, filsafat keindahan menjadikan filsafat sebagai objek formal, dan keindahan sebagai objek material, yang sekaligus dapat

1 Lihat John. S. Marshall, Art and Aesthetic in Aristotle, dalam The Journal of Aesthetics and Art Criticism, Vol. 12, No. 2, December 1953, hlm. 228-231. Dalam pernyataannya, Marshall mengatakan demikian : "The result of modern classical scholarship have made it abundantly clear that Aristotle's Poetics does not present us with an aesthetics, but with an analysis of poetic creation. There is in danger in contructing a theory of aesthetics from The Poetics, because the idea of imitation is not the source of Aristotle's philosophy of beauty. Imitation is a method of artistic constuction, but it is not the criterion of beauty. It has very unfortunate that Poetics has been trated as a manual of aesthetic, that is, as the exposition of a philosophy of Poetic beauty..."

2 Lihat Aristotle, Poetics, Trans. S.H. Butcher \& Francis Fergusson, Hill and Wang, New York, 1961. Pada paragraf kedua bagian pertama, dalam membuka pokok bahasannya Aristotle menyatakan demikian : "Epic Poetry and Tragedy, Comedy also and Dirthyrambic poetry, and the music of the flute and of the lyre in most of their forms, are all in their general conception mode of imitation. They differ, however, from one another in three respects-the medium, the objects, the manner of mode of imitation, being in each case distinct." 
ditafsirkan sebagai sebuah upaya penyelidikan sedalam-dalamnya, secara menyeluruh dan mendasar tentang hakikat keindahan. Keindahan dalam hal ini tentunya bersifat luas, dapat berupa nilai keindahan yang terdapat pada objek alam, manusia, sifat manusia, tindakan, benda seni, dan juga apapun yang ada di dunia ini. Tentunya ini merupakan pengetian yang sangat luas sekali, sebagaimana pengertian keindahan Socrates dan Platon yang mencakup pula ide tentang kebaikan dan juga keadilan. Estetika kini tidak lagi semata-mata membahas permasalahan filsafati, namun juga menyangkut batasan ilmiah berkaitan dengan karya seni seperti keindahan seni, pengalaman estetis, gaya ataupun aliran, maka estetika kini merupakan lingkup bahasan ilmiah.3 Artinya, estetika kini berada dalam ranah ilmu pengetahuan, dengan kata lain, ia sudah diluar lingkup filsafat sehingga kurang tepat jika istilah estetika digantikan (atau dipergunakan secara bergantian) dengan filsafat keindahan. Sejalan dengan hal tersebut, Gie pada akhirnya juga memahami estetika sebagai gugus pengetahuan (ilmu pengetahuan), nampak bagaimana ia membagi estetika menjadi dua bagian, yakni estetis filsafati (estetis tradisional) dan estetis ilmiah. Estetis filsafati adalah estetis yang menelaah sasarannya secara filsafati dan sering disebut sebagai estetis tradisional. Adapun estetis empiris atau estetis ilmiah adalah estetis yang meneliti dengan metode-metode ilmiah, yang bukan lagi merupakan cabang filsafat. Estetis ilmiah sering disebut juga sebagai estetis modern untuk membedakannya dengan estetis tradisional yang bersifat filsafati.4

\section{Bagan 1. Estetika sebagai gugus pengetahuan}

(Sumber : Gie, 1983:21)

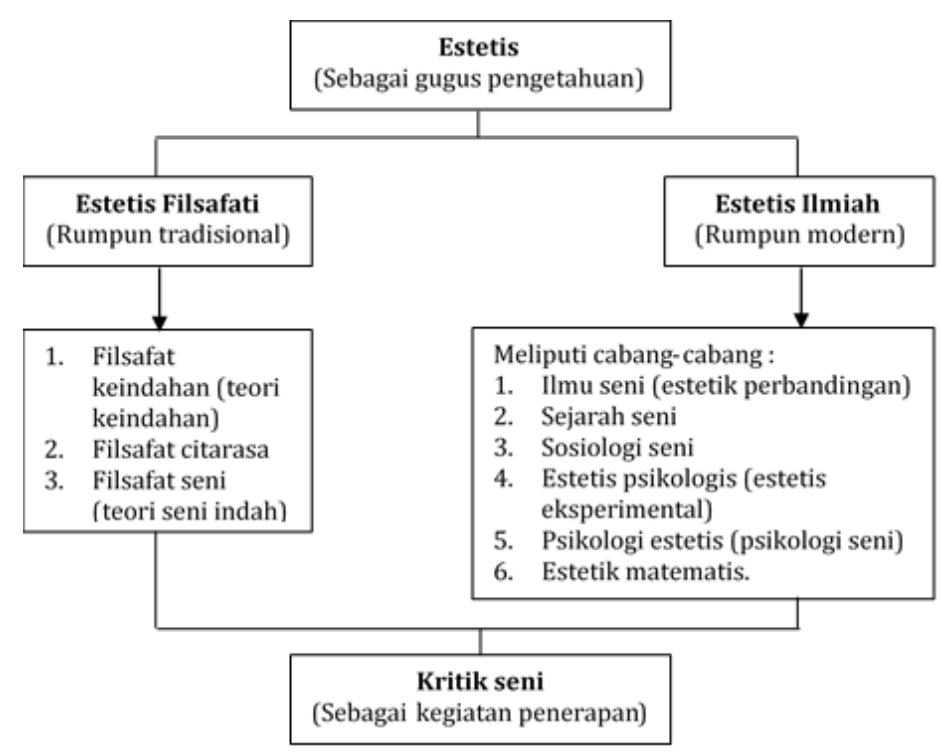

3 Lihat Sony Dharsono Kartika, dan Nanang Ganda Perwira, Pengantar Estetika, Penerbit Rekayasa Sains, Bandung, 2004, hlm. 5

4 Lihat The Liang Gie, Filsafat Seni : Sebuah Pengantar, Pusat Belajar Ilmu Berguna (PUBIB), Yogyakarta, 1983, hlm. 21.

Volume 2 No. 1.2018 | 52 
Karena bersifat interisiplin, estetika dalam rumpun modern tidak hanya memiliki orientasi kajian pada objek, namun juga subjek dan juga proses mental yang terjadi. Hal-hal tersebut dapat meliputi seniman, nilai seni, benda seni, pengalaman seni oleh penikmat seni (pengalaman artistik), pengalaman seni oleh pencipta seni (pengalaman estetik), dan juga publik seni. Apa yang dikemukakan oleh Marshall mengenai Poetics yang menjelaskan bahwa Imitasi adalah metode konstuksi artistik (yang tidak lain adalah pengalaman seni oleh pencipta seni), dalam perspektif estetis ilmiah sudah barang tentu merupakan konsep estetika, yang dalam hal ini adalah konsep estetika Aristotle, dan estetika tidak melulu berbicara tentang teori keindahan ataupun kriteria keindahan. Dalam Poetics, melalui konsep Tragedy dan katarsis, Aristotle membicarakan "keindahan" melampaui pengertian keindahan sebagai perasaan indah yang menyenangkan.5 Setidaknya ada dua pertimbangan untuk sedikit tidak bersepakat dengan pendapat Marshall yang menyatakan bahwa Poetics tidak menghadirkan teori estetika, namun ia merupakan sebuah analisis yang dilakukan Aristotle terhadap metode penciptaan karya sastra. Pertimbangan yang pertama, yakni menjadi kurang pas jika mendudukan estetika hanya pada gugus filsafat (terlebih filsafat keindahan) yang hanya berorientasi pada objek estetik, lalu di satu sisi menafikkan aspek-aspek yang lain seperti seniman, publik seni, nilai seni, dan juga pengalaman seni. Apa yang dikatakan Marshall sebagai "imitation is a method of artistic constuction" juga merupakan rumusan estetika, karena estetika tidak melulu berbicara tentang kriteria keindahan. Kedua, Marshall menempatkan estetika sebagai filsafat keindahan (philosophy of beauty), lalu menggunakan kedua istilah tersebut (estetika dan filsafat keindahan) secara bergantian, padahal, "keindahan" ("beauty"), karena beberapa alasan, sudah tidak memiliki kapasitas lagi untuk menjelaskan seni hari ini. Apa yang disampaikan oleh Aristotle dalam Poetics menjadi cukup relevan ketika dibicarakan dalam paradigma estetik modern. Menurut tradisi penafsiran yang panjang, Aristotle lazim dianggap mengajukan suatu posisi pemikiran estetika yang menyerupai formalisme dalam estetika modern. 6

5 Istilah "keindahan" sudah tidak memadai lagi ketika dipergunakan untuk menjelaskan seni. "Keindahan" dalam pengertian rasa indah yang menyenangkan tidak selalu hadir dalam penikmatan seni. Justru rasa takut, iba, atau kasihan kerap mewarnai proses mental dalam penikmatan karya seni. Hal ini sebagaimana yang diungkapkan oleh Aristotle sebagai katarsis. Hal ini dapat diilustrasikan seperti foto "Starving Child and Vulture" (1993), karya Kevin Carter (1960-1994), seorang fotografer Afrika Selatan. Foto ini menyajikan adegan seorang anak kecil kulit hitam bertubuh kurus tertelungkup di tanah (yang nampaknya kelaparan dan menjelang ajalnya), dan tidak jauh darinya terdapat seekor burung bangkai yang seolah-olah bersiap menyantap anak itu. Foto tersebut merupakan karya seni, namun bersamaan dengan itu, sama sekali tidak ada "keindahan" dalam pengertian rasa indah yang menyenangkan dalam foto itu. Carter memenangkan penghargaan fotografi Pulitzer Prize untukitu, namun dia bunuh diri dua bulan setelah memenangkan penghargaan tersebut di dalam truk di tebing sungai Braamfonteinspuit, Johannesburg, Afrika selatan.

6 Lihat Martin Suryajaya, Sejarah Estetika, Penerbit Gang Kabel, Jakarta, 2016, hlm. 54 - 55. Dalam bukunya Suryajaya menjelaskan bahwa tradisi penafsiran tersebut umumnya menempatkan posisi Aristotle berlawanan dengan estetika moralis gurunya Platon, yakni dengan mengajukan pandangan bahwa karya seni mesti dinilai dari elemen-elemen formal-inrinsiknya semata. Namun tafsiran semacam ini belakangan mulai digugat di kalangan klasikis. Suryajaya melanjutkan, bahwa kendati Aristotle memberikan beberapa pertimbangan yang mengarah pada kecenderungan formalis dalam evaluasi nilai karya seni, tetapi ia menempatkan pertimbangan-pertimbangan tersebut dalam konteks yang kurang lebih bercorak fungsional seperti halnya Plato. Meskipun pada akhirnya pemikiran Aristotle bercorak fungsional, namun kecenderungan formalis pada pemikiran Aristotle menjadikannya cukup relevan dalam paradigma estetika modern, atau mungkin dapat dikatakan sebagai proto-formalisme untuk tidak menyebut Aristotle seorang formalis, serta menghindari anakronisme. 
Aristotle lahir pada tahun 384 SM di Stageira, sebuah kota di Yunani Utara. Ayahnya adalah seorang dokter pribadi Amyntas II, raja Macedonia. Pada usia 17 atau 18 tahun, Aristotle dikirim ke Athena untuk belajar di Akademia Platon, sampai kemudian Platon meninggal pada tahun 348 SM. 20 tahun Aristotle belajar di Akademia Platon, di sana ia menerbitkan beberapa karya (Logic dan Rhetoric), mejadi "dosen" setelah sebelumnya menjadi "asisten dosen", dan mengampu "matakuliah" Logika dan Retorika.7 Dalam Poetics, Aristotle mendiskusikan secara sistematis kriteria formalis dalam menganalisis karya seni, khususnya sastra. Aristoteles memberikan perhatian khusus untuk membahas secara sistematis hubungan antar elemen dalam karya, yang merupakan aspek yang lebih dekat dengan pengertian Modern tentang bentuk karya seni.8 Namun kecenderungan formalis Aristotle hendaknya disikapi sebagai "gejala", karena memang tidak sepenuhnya formalistik sebagaimana dalam pengertian Modern, dan kita akan melihat itu dalam Poetics.9

\section{TENTANG POETICS}

Dalam bagian pertama Poetics, di awal paragraf dan di awal kalimatnya Aristotle telah menyatakan bahwa ia akan memperlakukan puisi dalam dirinya sendiri (poetry in itself), mencatat kualitas-kualitas penting, menyelidiki struktur plot, mengetahui sifat-sifat tiap bagian-bagian (elemen) di mana sebuah puisi disusun. Di bagian awal ini Aristotle nampak sudah menunjukkan kecenderungannya terhadap formalisme.10 Selanjutnya Aristotle menjelaskan tentang jenis-jenis puisi (tentunya dalam bulatan sastra Yunani Klasik) yang diantaranya (1) tragedy, (2) dithyramb, (3) komedi, (iambic, drama, ainos, diagramma, satire, poemata, epic, rhetoric, amphi geneseos, dan accoustic. Seni sebagai imitasi, menurut Aristoteles dapat dibedakan menurut beberapa hal, yakni : 1) medium imitasinya; 2) objek imitasinya; dan 3) Bagaimana imitasi dilakukan.11Dengan mendudukan seni sebagai mimesis, maka seniman melalukan peniruan sebuah obyek dengan menggunakan bentukbentuk dan warna-warna, para musisi melakukan peniruan dengan menggunakan irama, bahasa, dan melodi, sedangkan penari melakukan peniruan atas sifat-sifat, perasaan, dan juga tindakan dengan menggunakan irama saja. Berkaitan dengan itu, maka bentuk, irama, warna,

7 Lihat Bertens, K, Sejarah Filsafat Yunani, Edisi Revisi, Penerbit Kanisius, Yogyakarta, 2017, hlm. 154.

8 Martin Suryajaya, op.cit., hlm. 56

9 Istilah formalisme mengacu penekanan pada bentuk ketimbang konten (isi) atau makna dalam seni, sastra, ataupun filsafat. Seseorang yang mepraktikkan ini (formalisme) disebut formalis. Seorang formalis, dalam beberapa disiplin keilmuan dan juga filsafat, berpendapat bahwa tidak ada makna transenden terhadap disiplin itu selain konten literal yang tercipta. Di dalam Sastra, formalisme adalah mazhab/aliran kritik sastra dan teori sastra yang terutama melalukan studi tentang sebuah teks tanpa memperhitungkan pengaruh dari luar. Formalisme menolak, atau terkadang hanya memasukkan ke dalam "tanda kurung" hal-hal eksternal seperti konteks sosio-kultural, kepengarangan, konten, dan sebaliknya berfokus pada mode, genre, wacana, dan bentuk.Dalam seni rupa, Formalisme adalah doktrin atau praktik penekunan yang saksama terhadap bentuk yang bercorak atau bentuk-bentuk eksternal lain. Corak-corak elemen formal adalah garis, bentuk, warna dan sebagainya, yang dapat dikombinasikan untuk memproduksi keseluruhan gaya dan efek. Mengenali formalisme dalam seni lihat Laurie Scheneider Adams, A History of Western Art, McGraw-Hill, New York, 2017, hlm. 9

10 Aristotle, Poetics, Trans. S.H. Butcher \& Francis Fergusson, Loc..Cit., "I Propose to treat of Poetry in itself and of its various kinds, noting the essential quality of each, to inquire into the structure of the plot as requisite to a good poem; into the number and nature of the parts of which a poem is composed; and similarly into whatever else falls within the same inquiry. Following, then, the order of nature, let us begin with the principles which come first." (Chapter I)

11 Ibid., They differ,however, from one another in three respects- the medium, the objects, the manner or mode of imitation, being in each case distinct. (Chapter I) 
bahasa, dan melodi disebut oleh Aristotle sebagai medium peniruan (medium of imitation), yang dapat berbeda-beda pada setiap bentuk seni (seni rupa, sastra, tari, dan musik).12

Sebagai mimesis, karya seni dibuat oleh seniman dengan jalan melakukan peniruan terhadap obyek-obyek, peristiwa, dan tindakan-tindakan, maka gambaran manusia dalam karya itu harus ditiru dalam beberapa kategori moral sebagai watak, yakni : (1) Lebih baik daripada kita; (2) Lebih buruk daripada kita; atau (3) Sama dengan kita. Hal ini yang akan menjadi perbedaan antara Tragedi dan Komedi. Tragedi mempertontonkan manusia dengan lebih baik, sedangkan komedi mempertontonkan manusia dalam keadaan yang lebih buruk daripada kenyataannya.13 Pembahasan yang ketiga setelah medium dan objek imitasi, yakni cara imitasi tersebut dilakukan, Aristotle mengemukakan : 1) Menggunakan narasi, yang dapat capai dengan dua jalan yakni dengan menjadi tokoh yang lain, atau tetap menjadi dirinya, tanpa ada perubahan sama sekali; dan 2) Menggunakan tindakan atau peristiwa. Terkait mimesis, Aristotle memberikan dua pernyataan yang cukup menarik. Pertama, kehendak manusia untuk meniru sudah ada semenjak masih kecil, dan denga meniru itulah manusia belajar, mendapatkan pengetahuan-pengetahuannya yang pertama. Kedua, setiap orang menyukai karya-karya mimetik, karena manusia selalu menghubungkannya dengan pengalaman aktual. Aristotle lalu mencontohkan bahwa kita menyukai detail-detail pada gambar entah karena teknik yang digunakan ataupun pewarnaan, yang di satu sisi kita sendiri tidak begitu senang ketika melihat sasuatu itu dalam bentuk aslinya (obyek aslinya).14 Jika sebuah gambar/lukisan tidak memiliki acuan peniruan (obyek asli), maka gambar tersebut akan menimbulkan kesenangan oleh karena teknik yang dipergunakan, ataupun warna.

Aristotle mengmukakan bahwa Tragedi lahir karena improvisasi yang dilakukan terhadap epic, sedangkan komedi lahir dari improvisasi yang dilakukan terhadap lampoon (olok-olok, satire). Keduanya (Tragedi dan komedi) merupakan bentuk yang lebih agung daripada sebelumnya. Hal ini dikarenakan Tragedi membuang alur yang remeh temeh dan diksi yang bersifat komikal. Komedi menyajikan jenis manusia yang lebih buruk, yang di dalamnya juga mencakup kelucuan (sesuatu yang menggelikan). Kelucuan adalah kesalahan dan juga keburukan namun tidak menyakitkan, atau keburukan tanpa penderitaan.15 Pada bab VI Poetics, Aristotle mendefinisikan Tragedi, yakni merupakan imitasi dari tindakan (action) yang serius, menyeluruh, dan memiliki ruang lingkup tertentu, yang diwujudkan dengan cara bicara atau ujaran yang diperindah, dengan unsur-unsur yang terpisah, dalam lakon yang beragam, dalam tiruan yang berbentuk tindakan, bukan narasi, melalui rasa iba dan kengerian yang berimplikasi kepada penyucian jiwa melalui emosi-emosi yang muncul

12 Ibid., "Such, then, are the differences of the arts with respect to the medium of imitation" (Chapter I)

13 Ibid., "The same distinction marks off Tragedy from Comedy; for Comedy aims at representing men as worse, Tragedy as better than in actual life." (Chapter II)

14 Ibid., "The cause of this again is, that to learn gives the liveliest pleasure, not only to philosophers but to men in general; whose capacity, however, of learning is more limited. Thus the reason why men enjoy seeing a likeness is, that in contemplating it they find themselves learning or inferring, and saying perhaps, 'Ah, that is he.' For if you happen not to have seen the original, the pleasure will be due not to the imitation as such, but to the execution, the coloring, or some such other cause." (Chapter IV)

15 Ibid., "Comedy is, as we have said, an imitation of characters of a lower type- not, however, in the full sense of the word bad, the ludicrous being merely a subdivision of the ugly. It consists in some defect or ugliness which is not painful or destructive. To take an obvious example, the comic mask is ugly and distorted, but does not imply pain. " (Chapter V) 
tersebut.16 Aristotle juga mengungkapkan enam bagian (elemen, atau unsur), yakni (1) Alur (mythos); (2) watak (ethos); (3) Diksi (lexis); (4) Pemikiran (dianoia); (5) Spectacle (Opsis); dan (6) Nyanyian (melos). 17

\section{Unsur-unsur Tragedi}

\section{Alur/Plot}

Mengenai alur, Aristotle mengatakan bahwa elemen ini adalah inti, oleh kare itu ia merupakan jiwa dari tragedi, adapun karakter/perwatakan adalah yang kedua. Alur dalam Tragedi harus menyeluruh dan memiliki ruang lingkup. Menyeluruh dalam arti alur tersebut memiliki awal mula, pertengahan, dan kesimpulan/penutup. Dalam awal mula, adalah sesuatu yang tidak memerlukan sebab (mengikuti sesuatu yang lain), dan pada bagian pertengahan, peristiwa terjadi karena awal mula. Adapun bagian kesimpulan secara alamiah mengikuti apa yang sudah terjadi. Alur yang baik tidak bermula dan berakhir pada titik yang acak. Adapun ruang lingkup berhubungan dengan batasan ruang dan waktu hendaknya juga tidak ditentukan secara acak. Durasi hendaknya tidak terlalu panjang, dan peristiwa/tindakan tidak terlalu lebar untuk menghindari kebingungan penonton dalam melakukan pengamatan. Pendeknya, plot harus memiliki struktur peristiwa dan ukuran (panjang, atau semacam durasi) yang terukur.

Dalam Tragedi, hendaknya alur memiliki alur peristiwa tunggal, meskipun di dalamnya terdiri dari peristiwa-peristiwa banyak tokoh/karakter, ia harus menuju pada peristiwa/kejadian tunggal. Hal ini agar nampak adanya kesatuan dalam alur. Alur harus memiliki probabilitas, atau dapat dianggap sebagai sesuatu yang penting dalam menjalin hubungan antar satu episode dengan episode yang lain. Hal ini agar alur dapat menjadi lebih utuh, namun utuh saja tidak cukup, ia harus dapat memicu rasa iba/kasihan dan juga memunculkan kengerian. Rasa iba dan ngeri dapat muncul dengan baik ketika hal tersebut terjadi di luar dugaan penonton, namun tetap harus terjalin dalam hubungan sebab-akibat. Sebaiknya peristiwa yang bersifat kebetulan (aksidental) dihindari, namun jika harus dibuat, maka sedapat mungkin terjadi dalam hubungan sebab-akibat dengan rangkaian cerita.

Alur dalam Tragedi ada yang sederhana dan juga ada yang rumit. Alur dapat menjadi sederhana atau rumit oleh karena peristiwa dan tindakan yang disajikannya juga sederhana atau rumit. Peristiwa dan tindakan sederhana dalam arti tindakan tersebut merupakan peritiwa/tindakan tunggal, sedangkan alur yang rumit adalah peristiwa atau tindakan yang diikuti oleh penyingkapan tentang sesuatu yang tersembuyi atau pembalikan nasib. Penyingkapan dan pembalikan nasib tersebut harus muncul sebagai probabilitas dari

16 Penyucian (proper purgation) ini yang nampaknya disebut sebagai katarsis. Dalam bab VI Aristotle mengatakan demikian: "Tragedy, then, is an imitation of an action that is serious, complete, and of a certain magnitude; in language embellished with each kind of artistic ornament, the several kinds being found in separate parts of the play; in the form of action, not of narrative; through pity and fear effecting the proper purgation of these emotions".

17 Aristotle, Op.Cit., "Every Tragedy, therefore, must have six parts, which parts determine its quality- namely, Plot, Character, Diction, Thought, Spectacle, Song. Two of the parts constitute the medium of imitation, one the manner, and three the objects of imitation. " (Chapter VI) 
peristiwa/tindakan sebelumnya.18 Terkait dengan alur dalam Tragedi, terdiri dari komplikasi (perumitan masalah), dan penguraian. Komplikasi dapat tersusun dari peristiwa-peristiwa baik dari luar maupun dari dalam alur, sisanya merupakan penguraian.19 Komplikasi dalam Tragedi merupakan peristiwa-peristiwa yang dimulai di awal alur hingga pada bagian pembalikan nasib (perubahan menuju nasib baik atau nasib buruk). Sedangkan penguraian dalam Tragedi adalah peristiwa-peristiwa yang terjadi sejak awal terjadinya perubahan nasib hingga pada akhir. Penyair yang baik tentunya mempertimbangkan kedua hal tersebut dengan seimbang.

\section{Watak/Karakter dan Perwatakan}

Tanpa peristiwa, tindakan, atau adegan, Tragedi tidak akan ada. Namun tanpa watak mungkin saja Tragedi bisa ada. Para pemain drama itu tidak sedang berakting untuk meniru suatu watak tertentu, namun mereka memasukkan watak untuk kepentingan tindakan/adegan mereka. Perwatakan yang bagus, belum tentu dapat membentuk Tragedi yang bagus. Namun kecakapan membuat diksi dan perwatakan diperlukan sebelum seorang penyair dapat membuat alur yang bagus. Terkait dengan perwatakan, ada empat hal yang harus diperhatikan oleh seorang penyair, di antaranya :

1) Watak harus bagus/mencerminkan kebaikan. Inilah yang pertama dan paling penting. Watak yang bagus dapat dicapai ketika ia (karakter) mampu membuat jelas suatu keputusan. Watak yang bagus dapat ada pada peran apapun, baik itu perempuan ataupun budak, sebab biasanya keduanya itu inferior.

2) Watak harus memadai, semisal kejantanan dan kepandaian tidaklah memadai/tidak pantas jika dimiliki oleh seorang perempuan. 20

3) Watak harus sebagaimana kenyataan dalam hidup (true to life), yakni dengan membuatnya dengan bagus dan memadai (poin pertama dan kedua).

4) Watak/karakter harus konsisten. Bahkan ketika suatu peran itu mencermikan watak yang tidak konsisten, maka ia harus konsisten dalam ketidakkonsistenan.

Terkait dengan perwatakan, berhubung Tragedi adalah tiruan dari kehidupan orangorang yang secara moral lebih baik daripada umumnya, maka pelukis potret mungkin perlu dijadikan contoh. Mereka, sementara mereproduksi objek aslinya, membuat kemiripan yang sesuai kenyataan kehidupan, namun dikerjakan lebih indah. Pelukis itu melukis potret orang benar-benar seperti hidup, namun mereka melukisnya juga dengan lebih lembut daripada yang sebenarnya. Begitu juga dengan seorang penyair, ketika menyusun watak orang yang pemarah, malas, atau lainnya, penyair harus membuatnya benar-benar dalam sifat itu sekaligus membuatnya menjadi lebih pantas. 21

18 Ibid., "A Complex action is one in which the change is accompanied by such reversal, or by Recognition, or by both. These last should arise from the internal structure of the plot, so that what follows should be the necessary or probable result of the preceding action." (Chapter $\mathrm{X}$ )

19 Ibid., "Every tragedy falls into two parts- Complication and Unraveling or Denouement. Incidents extraneous to the action are frequently combined with a portion of the action proper, to form the Complication; the rest is the Unraveling." (Chapter XVIII)

20 Ibid., "The second thing to aim at is propriety. There is a type of manly valor; but valor in a woman, or unscrupulous cleverness is inappropriate." (Chapter XV)

21 Ibid., "Again, since Tragedy is an imitation of persons who are above the common level, the example of good portrait painters should be followed. They, while reproducing the distinctive form of the original, make a likeness which is true to life and yet more beautiful. So too the poet, in representing men who are irascible or indolent, or have other defects 


\section{Pemikiran (Tought)}

Pemikiran (tought) menurut Aristotle adalah kemampuan untuk mengatakan apa saja yang mungkin dan pantas/memadai, yang berfungsi dalam pembicaraan tentang kehidupan yang umum dan juga retorika. Pemikiran di samping itu adalah sesuatu yang dipergunakan untuk menunjukkan bahwa sesuatu itu terbukti atau tidak.22 Efek emosional dihasilkan oleh pembicaraan yang memiliki substansi pada pemikiran, Beberapa efek emosional yang dapat dihasilkan melalui pemikiran yakni : (1) Pembuktian atau sanggahan; (2) Perasaan-perasaan iba, kasihan, kengerian, marah, dan sebagainya; (3) Perbedaan pendapat mengenai penting atau tidak pentinya sesuatu. Efek-efek yang muncul ini bergantung kepada pembicaraan atau ucapan sang aktor. Mengenai pemikirian, Aristotle tidak banyak membahas, bahasan mengenai hal ini ada pada karyanya yang lain, Rhetorics.23

\section{Diksi}

Diksi, dalam pengertian Aristotle adalah komunikasi dengan menggunakan bahasa, ekspresi makna dalam kata, yang memiliki esensi sama pentingnya dalam sajak ataupun prosa.24 Jenis-jenis kata dibagi menjadi dua macam, yakni : (1) Sederhana, dan (2) Ganda. Tentang yang bersifat ganda terdiri dari bagian yang signifikan dan bagian yang tidak signifikan. Kata juga ada yang triple ataupun quadrupel, bahkan multiple, dan tentunya jauh lebih kompleks.25 Setiap kata dapat diungkapkan dalam beberapa mode : (1) Standar saja; (2) Eksotis (aneh); (3) Metaforik; (4) Ornamental; (5) Diciptakan baru (newly-coined); (6) Dipanjangkan; (7) Dikurangi; (8) Diubah.

Diksi yang baik adalah ketika diksi itu jelas dan unik. Diksi yang disusun dari katakata yang standar biasanya biasa-biasa saja. Diksi yang tidak biasa adalah yang diungkapkan dengan metaforik, eksotis, dipanjangkan, dan apapun itu yang tidak pada umumnya. Namun jika terlalu banyak diksi yang unik (metaforik, eksotis, dsb.), atau distilisasi, maka puisi itu akan menjadi sebuah teka-teki yang sulit dipahami, atau semacam racauan. Agar jelas dan juga bagus, maka perlu dikombinasikan, antara kata-kata yang metaforik tersebut dan dan dengan yang standar.

of character, should preserve the type and yet ennoble it. In this way Achilles is portrayed by Agathon and Homer. (Chapter $X V)$.

22 Third in order is Thought- that is, the faculty of saying what is possible and pertinent in given circumstances...Thought, on the other hand, is found where something is proved to be or not to be.." (Chapter VI)

23 Ibid., "Concerning Thought, we may assume what is said in the Rhetoric, to which inquiry the subject more strictly belongs." (Chapter XIX)

24 Ibid., "Fourth among the elements enumerated comes Diction; by which I mean, as has been already said, the expression of the meaning in words; and its essence is the same both in verse and prose." (Chapter VI)

25 Aristotle mencontohkan hal ini dengan nama seseorang, Hermo-caico-xanthus, yang berarti "Ia yang berdoa kepada Zeuz". (Chapter XXI). Ibid.

Volume 2 No. 1.2018 | 58 


\section{Nyanyian dan Spectacle (Tontonan)26}

Aristotle tidak banyak memberikan penjelasan mengenai dua hal ini di dalam Poetics. Aristotle hanya mengatakan bahwa nyanyian merupakan bagian yang juga sangat penting dalam Tragedi. Adapun spectacle, dapat dipahami sebagai "tontonan", atau keseluruhan tata panggung dan pola adegan/tindakan dalam pementasan drama, termasuk penyutradaan. 27 Aristotle menyatakan bahwa diantara semua elemen Tragedi, Spectacle adalah yang nampak paling memukau, namun memiliki hubungan yang paling lemah dengan puisi (tragedi).

Seorang penyair yang baik mampu membuat Tragedi yang bagus, mampu menggugah emosi penonton tanpa harus mengandalkan tata panggung dan efek-efek spektakuler. Lagi pula, tata panggung yang megah, efek-efek spektakuler merupakan hal-hal di luar kepenyairan, dan lebih kepada keterampilan desainer panggung, atau jika dimaknai dalam konteks masa kini mungkin semacam "stage manager/designer" dalam Event Organizer. Lebih lanjut Aristotle juga mengungkapkan bahwa kengerian dan rasa iba dapat muncul dari Spectacle, namun yang lebih baik adalah muncul dari struktur peristiwa itu sendiri, dan ini merupakan ciri seorang penyair yang unggul. Penyair yang semata-mata mengandalkan Spectacle dalam dramanya adalah penyair yang kurang cerdik dan membuang-buang biaya produksi, karyanya hanya dahsyat namun sama sekali tidak mengerikan.

\section{Tentang Nasib, Adegan Tragis, dan Kengerian}

Seorang penyair (sastrawan/seniman) tidak bertugas/berfungsi untuk menguraikan apa yang sesungguhnya terjadi, namun menguraikan segala apa yang mungkin terjadi sesuai dengan hukum probabilitas. Di sinilah perbedaan antara seorang penyair dengan seorang sejarawan. Dalam bentuknya, penyair menulis karyanya (apa-apa yang mungkin terjadi) dalam bentuk prosa, sedangkan sejarawan menulis (apa yang telah terjadi) dalam bentuk sajak. Maka dari itu, puisi lebih bersifat filosofis dan serius dibanding sejarah.

Tentang alur yang rumit sebagai peristiwa atau tindakan yang diikuti oleh penyingkapan tentang sesuatu yang tersembuyi atau pembalikan nasib. Penyingkapan dan pembalikan nasib tersebut harus muncul sebagai probabilitas dari peristiwa/tindakan sebelumnya. Adapun pembalikan nasib adalah perubahan suatu kondisi menuju kepada kebalikannya sebagaimana hukum probabilitas dan keniscayaan.28 Penyingkapan, adalah perubahan dari ketidaktahuan menuju pengetahuan, dan juga dapat pula berupa pertemanan

26 Dalam kamus, "Spectacle" sering diterjemahkan sebagai segala sesuatu yang dipaparkan pada pandangan manusia, biasanya bersifat impresif, atau memukau. Semacam pertunjukan atau penampilan di muka publik, terutama dalam skala besar. Merriam-Webster menerjemahkan "Spectacle" sebagai "something exhibited to view as unusual, notable, or entertaining; especially: an eye-catching or dramatic public display”.

27 Pengertian ini diambil dari catatan kaki oleh editor dalam Aristoteles, Puitika: Seni Puisi, Penerbit Basa Basi, Yogyakarta, 2017, hlm. 28. Buku ini merupakan terjemahan bahasa Indonesia dari Aristotle Poetics terjemahan Richard Janko (1987). Dalam buku tersebut, ada hal yang menjadi keberatan penulis, terutama mengenai penggunaan term "representasi" untuk menggantikan "mimesis", padahal keduanya ada pada kategori konsep yang berbeda. Representasi dapat dimaknai sebagai suatu tindakan menghadirkan sesuatu dengan sesuatu yang lain di luar dirinya, sedangkan mimesis adalah meniru. Sebagai "tiruan" tentunya ia memiliki kesamaan kualitatif dengan objek (sesuatu) yang ditiru, atau dengan perkataan lain ia bersifat "ikonis". Dalam representasi, representamen tidak selalu memiliki kesamaan kualitatif dengan obyek acuan (ikonis), ia dapat bersifat simbolik, atapun indeksikal.

28 Ibid., "Reversal of the Situation is a change by which the action veers round to its opposite, subject always to our rule of probability or necessity. " (Chapter XI) 
menuju ke permusuhan, yang tentunya berkaitan dengan nasib baik atau kemalangan (pembalikan nasib). Pembalikan nasib dan penyingkapan merupakan dua bagian alur yang menjelma dalam urutan permulaan, pertengahan, dan kesimpulan dalam Tragedi. Penderitaan (pathos) adalah adegan "merusak" atau yang menyakitkan, misalnya kematian, nyeri, luka, dan sebagainya.29

Lalu jenis adegan/peristiwa seperti apa yang mampu membangkitkan kengerian dan rasa iba (tragis)? Adegan atau peritiwa tersebut harus ditempatkan dalam aktor-aktor yang memiliki hubungan dekat, bisa teman atau keluarga. Hal yang wajar ketika melihat adegan musuh yang membunuh musuh, atau pembunuhan yang terjadi diantara orang yang bukan teman atau musuh, tidak ada rasa iba atau ngeri yang muncul. Namun lain halnya jika pembunuhan itu terjadi oleh aktor-aktor yang memiliki hubungan dekat, semisal anak membunuh ibunya atau sebaliknya, atau seseorang yang tanpa sadar telah membunuh (atau nyaris membunuh) sahabatnya. Aristotle kemudian mencontohkan sebagai berikut : (1) Beritindak dengan sadar dan tahu, sebagaimana Euripedes yang membuat Medea membunuh anaknya; (2) Aktor sadar harus bertindak, ia benar-benar tahu tetapi tidak melakukannya, akhirnya ia tenggelam dalam kubangan penderitaan; (3) Aktor sadar harus bertindak, namun ia bertindak (berbuat mengerikan) tanpa sadar atau dalam ketidaktahuannya; atau (4) Nyaris melakukan sesuatu yang mengerikan namun dalam ketidaktahuan, tetapi mengakui itu sebelum melakukannya.30 Diantara keempatanya, cara yang kedua, aktor sadar harus bertindak, ia benar-benar tahu tetapi tidak melakukannya, adalah cara yang terburuk. Cara yang terakhir (keempat), menurut Aristotle adalah yang terbaik.

Tragedi yang baik memiliki alur yang rumit, menyajikan peristiwa/adegan-adegan yang mengerikan dan menyedihkan, sebagai tiruan dari tindakan dan kehidupan manusia. Di samping memuat salah satu dari empat adegan tragis yang sudah disampaikan diatas, Tragedi, sebaiknya menghindari beberapa hal ini:

1) Menyajikan orang-orang baik (yang diterima dengan baik oleh publik), yang menjalani perubahan dari nasib baik ke nasib buruk. Hal ini tentunya biasa saja, tidak begitu mengerikan atau menyedihkan.

2) Orang-orang berperangai buruk yang menjalani perubahan dari nasib buruk menjadi baik. Sajian ini sama sekali tidak tragis dan tidak memberikan kepuasan moral.

3) Orang-orang yang berperangai buruk, keji, dan kejam tak terkira, yang mengalami nasib baik, kemudian menjadi bernasib buruk. Sajian ini mungkin memberikan kepuasan moral kepada penikmat, namun biasa saja, tidak tragis, karena sudah selayaknya orang jahat mengalami nasib yang buruk.

29 Ibid., "A third part is the Scene of Suffering. The Scene of Suffering is a destructive or painful action, such as death on the stage, bodily agony, wounds, and the like." (Chapter XI)

30 Ibid., "The action may be done consciously and with knowledge of the persons, in the manner of the older poets. It is thus too that Euripides makes Medea slay her children. Or, again, the deed of horror may be done, but done in ignorance, and the tie of kinship or friendship be discovered afterwards. The Oedipus of Sophocles is an example. Here, indeed, the incident is outside the drama proper; but cases occur where it falls within the action of the play: one may cite the Alcmaeon of Astydamas, or Telegonus in the Wounded Odysseus. Again, there is a third case- [to be about to act with knowledge of the persons and then not to act. The fourth case] is when some one is about to do an irreparable deed through ignorance, and makes the discovery before it is done." (Chapter XIV). 
4) Yang terakhir, yakni sajian mengenai orang yang tidak lebih baik dari kita (orang pada umumnya) dalam hal moral, kebaikan, memiliki reputasi yang cukup baik, lalu mengalami nasib buruk bukan karena kejahatan atau keburukan yang ia lakukan, namun karena kesalahan fatal.

Tragedi yang baik, harus sesuai dengan prinsip-prinsip yang telah diutarakan diatas, dan juga, yang terbaik, adalah tragedi yang memiliki alur ganda.

\section{PENUTUP}

Dalam chapter VI Poetics, Aristoteles mendefinisikan tragedi sebagai Mimesis Praxeos, "imitation of action". "Praxis" atau "Tindakan" dalam konteks ini sering dimaknai merujuk pada tindakan yang disengaja dalam keadaan rasional dan sadar. "Praxis" merupakan istilah teknis yang kadang-kadang muncul dalam tulisan Aristotle yang lain, yakni Nicomachean Ethics. Di samping itu, "Action" (praksis) juga dimaknai bukan sebagai perbuatan, kejadian, atau aktivitas fisik, namun juga motivasi, yang merupakan asal muasal suatu perbuatan manusia bermunculan.31 Lepas dari definisi mengenai Praxis yang dimaksud oleh Aristotle, baik itu tindakan ataupun motivasi, hal ini menujukkan perbedaan konsep mimesis Aristotle (Mimesis Praxeos) dengan konsep mimesis gurunya, Platon.

Menurut Platon, seni adalah mimesis, atau tiruan alam. Oleh karena itu, bagi Platon, seni adalah buruk. Hal ini tidak lepas dari pemikirannya mengenai dunia ideal. Jadi, disamping dunia nyata (kenyataan duniawi) yang secara empirik kita alami dalam keseharian ini, terdapat 'dunia lain', yakni dunia ide. Di sana, di dunia ide, segalanya serba sempurna, dan segala yang ada di dunia nyata ini hanya merupakan penampakan atau cerminannya saja. Oleh karena itu, dunia nyata ini berada pada taraf yang lebih rendah daripada dunia ide. Mengenai hal ini, Platon memberikan contoh tentang pelukis/seniman yang melukis ranjang. Dalam dunia ide Platon ada bentuk ranjang yang sempurna dan abadi. Bentuk ranjang (yang sempurna) itu kemudian menjadi penampakan atau 'mewujud' ke dalam dunia nyata melalui keahlian seorang tukang kayu, sebagaimana ranjang-ranjang yang kita temui di kehidupan sehari-hari. Namun kemudian seorang seniman melukis ranjang di dunia nyata yang dibuat oleh tukang kayu tersebut ke dalam kanvasnya. Maka lukisan ranjang di atas kanvas itu merupakan tiruan dari ranjang di dunia nyata yang dibuat oleh tukang kayu, sedangkan ranjang tersebut hanyalah penampakan atau cerminan dari bentuk ranjang yang sempurna di dunia ide. Seni menurut Platon adalah buruk, karena : 1) Secara epistemologis, seni yang diperoleh dari imitasi tersebut mereduksi (menghilangkan) kenyataan atau kebenaran akan sesuatu; 2) Secara teologis, penyair dan juga seniman bertindak seolah-olah seperti Dewa/Tuhan dengan cara yang tidak pantas; 3) Secara moral dan psikologis, imitasi (peniruan) yang sangat baik oleh seniman, dapat merusak kestabilan manusia, bahkan manusia terbaik sekalipun, oleh karena seni dapat membuat orang menjadi sedih, depresi, dan meratapi kehidupannya (merusak akal). Dalam ide Platon tentang sebuah negara yang ideal

31 Lihat Elizabeth Belfiore, Aristotle's Concept of Praxis in the Poetics, dalam The Classical Journal, Vol. 79, No. 2 (Dec., 1983 - Jan., 1984), hlm. 110-124. Dalam tulisannya, Belfiore mengatakan demikian, "In Poetics 6, Aristotle defines tragedy as mimesis praxeos, "imitation of action". "Praxis" or "Action" in ths context is often taken to refer to the deliberate action in a rational being, a technical sense the term sometimes has in Aristotle's ethical writings. Fergusson for example, writes that "Action (praxis) does not mean dees, events, or physical activity : it means, rather, the motivation from which deeds spring." 
(dalam bukunya Republik), ia mencoret seniman, pelukis, dan penyair sebagai warga negara yang baik karena berbahaya bagi kehidupan bermasyarakat (Gie, 2004: 22).32

Alih-alih merangkum konsep estetika Aristotle dalam Poetics, tulisan ini mencoba menarik perbedaan yang cukup tajam antara Mimesis Praxeos (Aristotle) dengan Mimesis Platonik (Platon).33 Pertama, seni dalam Mimesis Platonik melakukan peniruan terhadap obyek, dan obyek itu hanyalah cerminan dari bentuk yang abadi di dunia ide, sedangkan dalam Mimesis Praxeos peniruan dilakukan terhadap kehidupan, tindakan fisik, perbuatan atau kejadian yang ada di alam nyata. Kedua, mimesis dalam konsep Platon adalah buruk, oleh karena ketiga hal yang sudah diungkapkan di atas, sedangkan dalam Mimesis Praxeos, peniruan adalah wajar, dan bahkan baik, karena kehendak manusia untuk meniru sudah ada semenjak masih kecil, dan denga meniru itulah manusia belajar, mendapatkan pengetahuanpengetahuannya yang pertama. Ketiga, dalam Mimesis Platonik, emosi sedih, meratap, dan kengerian-kengerian yang ditimbulkan oleh seni dapat merusak kestabilan dan akal manusia, sedangkan dalam Mimesis Praxeos, emosi-emosi semacam itu justru menggiring manusia kepada tindakan merefleksikan kehidupan dan penyucian jiwa (katarsis). Tidak menutup kemungkinan perbedaan-perbedaan tersebut akan bertambah ketika dilakukan penyelidikan lebih mendalam.

Mengenai pemikiran Aristotle yang cenderung Formalistik, meskipun pada akhirnya bercorak fungsional, artinya apa yang sudah disampaikan Aristotle dalam Poetics mengenai Tragedi atau seni drama yang baik, bermuara pada sajian tontonan yang bermutu dan mendidik. Hal ini juga dapat dikatakan bahwa sajian drama yang baik menjadikan masyarakat memperoleh pengertian tentang keutamaan moral. Alih-alih formalistik, pemikiran Aristotle berujung pada fungsionalisme.34 Terakhir, karya filsuf klasik Yunani semacam Poetics, dan juga yang lain nampaknya kurang tepat jika dimaksudkan untuk 'dirangkum', karena berpotensi tereduksi besar-besaran dan berakibat pada pemiskinan makna, untuk itu lebih tepatnya bukan dirangkum, namun 'diurai'.

\section{DAFTAR RUJUKAN}

Adams, Laurie Scheneider. 2017. A History of Western Art. New York : McGraw-Hill.

Aristotle. 1961. Poetics. Trans. S.H. Butcher \& Francis Fergusson. New York : Hill and Wang.

. 2017. Puitika. Trans. Richard Janko, Terjemahan oleh Cep Subhan. Yogyakarta : Penerbit Basabasi.

Belfiore, Elizabeth. 1984. Aristotle's Concept of Praxis in the Poetics, dalam The Classical Journal.Vol. 79, No. 2 (Dec., 1983 - Jan., 1984), hlm. 110-124.

32 The Liang Gie, Op.Cit., hlm. 22.

33 "Mimesis Platonik", mungkin istilah yang masih dapat diperdebatkan. Dengan tidak bermaksud membuat istilah baru, penggunaan istilah tersebut hanya dimaksudkan untuk mengontraskan konsep mimesis Platon dengan konsep mimesis Aristotle (Mimesis Praxeos).

34 Martin Suryajaya, Op.Cit., hlm. 65. "Dalam musik atau kesenian secara umum, apa yang penting bagi Aristoteles bukan sekadar menikmati, tetapi 'menikmati secara tepat' (khairein orthos). Konsep itu juga dijumpai dalam Plato. Kali ini obyek ketepatan itu adalah keutamaan moral masyarakat. Menikmati musik secara tepat berarti bukan hanya 'mendengar musik'- menikmati permainan harmoni, ritme, dan melodi, melainkan juga memahami signifikansi sosialnya. Artinya dalam penikmatan yang tepat atas musik kita memperoleh pengertian tentang keutamaan moral suatu masyarakat." 
Bertens, K. 2017. Sejarah Filsafat Yunani, Edisi Revisi. Yogyakarta : Penerbit Kanisius.

Gie, The Liang. 1983. Filsafat Seni : Sebuah Pengantar. Yogyakarta : Pusat Belajar Ilmu Berguna (PUBIB).

Kartika, Sony Dharsono, dan Nanang Ganda Perwira. 2004. Pengantar Estetika. Bandung : Rekayasa Sains, Bandung.

Marshall, John. S. 1953. Art and Aesthetic in Aristotle, dalam The Journal of Aesthetics and Art Criticism, Vol. 12, No. 2, December 1953, hlm. 228-231.

Suryajaya, Martin. 2016. Sejarah Estetika. Jakarta : Penerbit Gang Kabel. 